Sammlung Metzler

Band 315 
Hans-Jürgen Lüsebrink

\section{Einführung in die Landeskunde Frankreichs}

Wirtschaft - Gesellschaft - Staat - Kultur Mentalitäten 


\section{Der Autor}

Hans-Jürgen Lüsebrink, geb. 1952; Professor für Romanische Kulturwissenschaft und Interkulturelle Kommunikation an der Universität Saarbrücken; Gastprofessuren in Frankreich, Kanada, den USA, Dänemark, Österreich, Senegal und Burkina Faso.

Die Deutsche Bibliothek - CIP-Einheitsaufnahme

Lüsebrink, Hans-Jürgen:

Einführung in die Landeskunde Frankreichs /

Hans-Jürgen Lüsebrink.

- Stuttgart : Metzler, 2000

(Sammlung Metzler ; Bd. 315)

ISBN 978-3-476-10315-4

SM 315

ISBN 978-3-476-10315-4

ISBN 978-3-476-04027-5 (eBook)

DOI 10.1007/978-3-476-04027-5

ISSN 05583667

Dieses Werk einschließlich aller seiner Teile ist urheberrechtlich geschützt. Jede Verwertung außerhalb der engen Grenzen des Urheberrechtsgesetzes ist ohne Zustimmung des Verlages unzulässig und strafbar. Das gilt insbesondere für Vervielfältigungen, Übersetzungen, Mikroverfilmungen und die Einspeicherung und Verarbeitung in elektronischen Systemen.

(C) 2000 Springer-Verlag GmbH Deutschland

Ursprünglich erschienen bei J.B. Metzlersche Verlagsbuchhandlung und Carl Ernst Poeschel Verlag GmbH in Stuttgart 2000

www.metzlerverlag.de

Info@metzlerverlag.de 


\section{Inhalt}

1. Einleitung $\ldots \ldots \ldots \ldots \ldots \ldots \ldots \ldots \ldots \ldots \ldots \ldots \ldots$

2. Raum und Bevölkerung ................. 6

2.1 Vom kontinentalen zum außereuropäischen Frankreich . 6

2.2 Heterogenitäten des französischen Raums........... 9

2.3 Bevölkerungsentwicklung - von der Großzur Mittelmacht .................... 16

2.4 Einwanderungsland Frankreich $\ldots \ldots \ldots \ldots \ldots \ldots$

3. Wirtschaft ......................... 25

3.1 Vom Agrar-zum Industrieland ............ 25

3.2 Wirtschaftsentwicklung und Wirtschaftspolitik seit $1945 \ldots \ldots \ldots \ldots \ldots \ldots \ldots \ldots \ldots \ldots$.................. 31

3.3 Die französische Wirtschaft im Kontext der Globalisierung. .................... 41

4. Gesellschaft....................... 49

4.1 Zäsurerfahrungen und historische Traumata . . . . . . . 49

4.2 Modernisierungsprozesse $\ldots \ldots \ldots \ldots \ldots \ldots \ldots . \ldots 4$

4.3 Soziabilitätsformen (Familie, Vereine, Gewerkschaften) ................... 58

4.4 Soziale Problemfelder: Ungleichheiten, Arbeitslosigkeit, Marginalisierungsprozesse .................66 66

5. Staat und Nation ..................... 75

5.1 Der französische Staat - Kontinuitäten und Transformationen................... 75

5.2 Bildung und Erziehung $\ldots \ldots \ldots \ldots \ldots \ldots \ldots \ldots$

5.3 Nationalstaat und Nationalismus . . . . . . . . . . . 99

6. Politik .............................. 111

6.1 Das System der politischen Parteien:

Entstehungskontexte, Struktur, Profile ......... 111

6.2 Die Politische Kultur in Frankreich........... 126

6.3 Verfassungsentwicklung und Verfassungsstruktur .... 131

6.4 Außenpolitik......................... 140 
7. Kultur und Medien .................... 153

7.1 Die Civilisation Française - Identitätsbewusstsein und universeller Geltungsanspruch ........... 153

7.2 Intellektuelle Kultur: von den Avantgarden zur Figur des Intellectuel .................. 155

7.3 Massenmedien in Frankreich - globale Entwicklungstendenzen und französische Spezifika .......... 158

7.4 Exceptions françaises - Spezifika der französischen Kultur und Kulturpolitik .................. 164

7.5 Métissages - Regionalismus und Multikulturalität in der französischen Gegenwartskultur .......... 170

7.6 Deutsch-französische Kulturbeziehungen Bilanz und Perspektiven ................. 174

8. Bibliographie $\ldots \ldots \ldots \ldots \ldots \ldots \ldots \ldots \ldots \ldots$

Sachregister .......................... 194

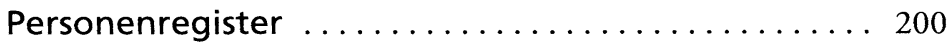

